IZA DP No. 7449

Exploitation, Altruism, and Social Welfare: An Economic Exploration

Matthias Doepke

June 2013 


\title{
Exploitation, Altruism, and Social Welfare: An Economic Exploration
}

\author{
Matthias Doepke \\ Northwestern University \\ and IZA
}

\author{
Discussion Paper No. 7449 \\ June 2013
}

IZA
P.O. Box 7240
53072 Bonn
Germany

\author{
Phone: +49-228-3894-0 \\ Fax: +49-228-3894-180 \\ E-mail: iza@iza.org
}

\begin{abstract}
Any opinions expressed here are those of the author(s) and not those of IZA. Research published in this series may include views on policy, but the institute itself takes no institutional policy positions. The IZA research network is committed to the IZA Guiding Principles of Research Integrity.

The Institute for the Study of Labor (IZA) in Bonn is a local and virtual international research center and a place of communication between science, politics and business. IZA is an independent nonprofit organization supported by Deutsche Post Foundation. The center is associated with the University of Bonn and offers a stimulating research environment through its international network, workshops and conferences, data service, project support, research visits and doctoral program. IZA engages in (i) original and internationally competitive research in all fields of labor economics, (ii) development of policy concepts, and (iii) dissemination of research results and concepts to the interested public.
\end{abstract}

IZA Discussion Papers often represent preliminary work and are circulated to encourage discussion. Citation of such a paper should account for its provisional character. A revised version may be available directly from the author. 


\section{ABSTRACT \\ Exploitation, Altruism, and Social Welfare: An Economic Exploration ${ }^{*}$}

Child labor is often condemned as a form of exploitation. I explore how the notion of exploitation, as used in everyday language, can be made precise in economic models of child labor. Exploitation is defined relative to a specific social welfare function. I first show that under the standard dynastic social welfare function, which is commonly applied to intergenerational models, child labor is never exploitative. In contrast, under an inclusive welfare function, which places additional weight on the welfare of children, child labor is always exploitative. Neither welfare function captures the more gradual distinctions that common usage of the term exploitation allows. I resolve this conflict by introducing a welfare function with minimum altruism, in which child labor in a given family is judged relative to a specific social standard. Under this criterion, child labor is exploitative only in families where the parent (or guardian) displays insufficient altruism towards the child. I argue that this welfare function best captures the conventional concept of exploitation and has useful properties for informing political choices regarding child labor.

JEL Classification: D63, D64, J10, J47, J80

Keywords: child labor, exploitation, social welfare function, altruism

Corresponding author:

Matthias Doepke

Department of Economics

Northwestern University

2001 Sheridan Road

Evanston, IL 60208

USA

E-mail: doepke@northwestern.edu

\footnotetext{
* I thank David de la Croix, Steven Durlauf, Ruben Gaetani, Jack Knight, Sebastian Kohls, Andreas Kropf, Veronika Selezneva, and participants at the 2012 PPE Conference "On Exploitation" in New Orleans for comments that helped to substantially improve the paper. Financial support from the National Science Foundation (grant SES-0820409) is gratefully acknowledged.
} 


\section{Introduction}

In both popular and scientific writing, child labor is frequently portrayed as a form of exploitation of children. ${ }^{1}$ Indeed, searching for ["child labor" and "exploitation"] on Google Scholar yields about 22,000 hits in June 2013. ${ }^{2}$ Yet within the context of economic models of child labor, there is usually no clearly defined notion of exploitation. To be sure, the literature has identified a number of conditions under which some restrictions of child labor may be desirable. However, these arguments are based on standard efficiency grounds (generated by, for example, human capital externalities) and are not linked to the concept of exploitation. ${ }^{3}$

In this paper, I explore how exploitation can be defined in the context of an economic model in a way that rhymes with the conventional understanding of the term. That is, I am taking seriously the moral intuitions that lie behind the usage of "exploitation" in common language, and aim to translate these intuitions into the language of welfare economics. Central to this undertaking is to develop a welfare criterion that can be used to decide which forms of child labor amount to exploitation, and which do not.

To see why this is not a trivial undertaking, consider the standard welfare concept used in dynamic economic models. Since the seminal work of Barro (1974) and Barro and Becker $(1988,1989)$, it has been standard practice to treat altruistically linked dynasties in a way that is analogous to a single agent who has an infinite lifespan. ${ }^{4}$ In the case of a single agent who lives forever, the natural welfare concept is the initial lifetime utility of the agent. If there are multiple such agents, the welfare criterion is a (possibly weighted) sum of lifetime utilities. Applying the same concept to a world of dynasties, a welfare criterion emerges that

\footnotetext{
${ }^{1}$ Child labor is still common in developing countries. According to the International Labour Organisation, there were 215 million working children in 2008.

${ }^{2}$ Examples from the literature in economics include Horrell and Humphries (1995) and Holleran (1995).

${ }^{3}$ See for example the discussions in Baland and Robinson (2000) and Doepke and Krueger (2006).

${ }^{4}$ See de la Croix and Michel (2002), Chapter 5, for a more extensive discussion of the modeling of altruism in macroeconomic models.
} 
evaluates the welfare of the entire dynasty through the utility of the head of the dynasty. Future members of a dynasty only enter consideration insofar as the initial member of the dynasty is altruistic towards them, i.e., their utility enters the utility of the dynasty head.

Defining a dynastic utility criterion in this way has practical advantages. Standard results from dynamic economics carry over to the dynastic setting, implying, for example, that in the absence of externalities and with complete markets competitive equilibria are efficient.

However, using the standard dynastic welfare criterion also makes it impossible to second-guess whether parents make the "right" choices for their children. The implicit social welfare function accepts the revealed preference of parents for their children, and does not attach any importance to the children other than through the altruism that their parents feel for them. This limitation of standard dynastic welfare explains why it is difficult to speak of exploitation of children in this class of economic models. When we feel that children are being exploited, implicitly we are saying that their parents (or, more generally, guardians) are not taking sufficient care of them. Yet such a judgement cannot be expressed when a welfare criterion is used that assumes from the outset that the parents care just the right amount. Hence, the standard dynastic social welfare function renders the concept of exploitation vacuous.

The aim of this paper is to address the mismatch between the rhetoric of exploitation and the welfare criteria that are usually applied to economic models. To do this, I propose alternative welfare criteria that can be used to give the term exploitation a more precise meaning within an economic model of child labor, and then connect this discussion to arguments for and against regulation of child labor. Based on the common-language understanding of exploitation, for the purposes of this paper we will say that people are being exploited if they are unfairly used for the benefit of others. ${ }^{5}$ In the case of child labor, the "being used for the benefit of others" condition will usually be satisfied, because it is generally parents (or other guardians) who make decisions on child labor and stand to benefit

\footnotetext{
${ }^{5}$ Of course, other definitions of exploitation are possible. For a Marxian perspective, see Roemer (1985).
} 
from the income. The question, then, is whether this use of the child is unfair. A number of different notions of fairness have been proposed by writers in ethics and political philosophy. My objective here is to stay as close as possible to conventional concepts of social welfare in economic models, while also arriving at a formulation that gives meaning to the term exploitation. The notion of fairness will therefore be based on social welfare functions that are ultimately based on individual preferences. ${ }^{6}$ In addition, a criterion is desired under which the question of whether child labor amounts to exploitation does not have an absolute answer, but rather depends on specific circumstances. This will reconcile, through the lens of the formal criterion, the common intuition that, for example, extreme forms of child labor such as prostitution constitute exploitation, whereas activities such as helping out on the family farm are more benign. In evaluating different social welfare functions, I will be looking for criteria where such gradual judgements are possible.

To find a notion of fairness that meets these objectives, it is essential to allow a distinction between parental altruism and the "social" altruism that is used to define exploitation. In particular, the basic idea of the welfare criteria proposed here is to allow for social welfare functions that may give more (or less) weight to children than the weight implicit in their parents' altruism. Whether child labor amounts to exploitation then depends on the degree of parental altruism. Indeed, if a parent had no regard whatsoever for the welfare of the child, child labor would be akin to slavery, and presumably slavery should amount to exploitation under any definition. Conversely, if a parent had complete disregard for his or her own utility and was solely motivated by maximizing the child's happiness, child labor would only occur to benefit the child, and thus should not constitute exploitation. Unlike the standard dynastic social welfare function, the preferred social welfare function developed here leads to the same conclusions.

In the following section, I outline a basic model of child labor that will provide the framework for the analysis. Section 3 contains the core of the analysis and outlines how exploitation does or does not arise from the perspective of alterna-

\footnotetext{
${ }^{6}$ Thus, I follow the utilitarian approach to social welfare, as discussed, for example, by Sen (1979).
} 
tive criteria for judging social welfare. Section 4 concludes.

\section{A Simple Model of Child Labor and Altruism}

While the arguments below should be applicable to a wide class of economic models, it is useful to develop the main ideas in a specific setting. The key features of the environment considered here are that there are parents and children; parents decide on child labor; and parents are altruistic towards their children. To simplify the analysis, the main ideas are developed in a static setting with a single generation of parents and children. ${ }^{7}$ A dynamic extension is considered in Section 3.6 below.

\subsection{Economic Environment}

We envision an economy populated by a finite number of adults, indexed by $i$, who are characterized by their human capital $h_{i}>0$ and a preference parameter $z_{i}$, where $0 \leq z_{i} \leq 1$. Each adult has exactly one child. The preference parameter $z_{i}$ represents altruism, i.e., the relative weight of the child's utility in the utility function of the parent. There may be variation in the degree of altruism among the parents. The parent's lifetime utility $V_{P, i}$ as a function of human capital $h_{i}$ is given by:

$$
V_{P, i}\left(h_{i}\right)=\left(1-z_{i}\right) u\left(c_{P}\left(h_{i}, l_{i}\right)\right)+z_{i} V_{C}\left(h_{C}\right) .
$$

Here $c_{P}\left(h_{i}, l_{i}\right)$ is the parent's consumption (which depends on human capital and the supply of child labor) and $V_{C}$ is the child's utility (as an adult). The parent works full time, and chooses the child's labor supply $l_{i}$. The remaining time $1-l_{i}$ serves to raise the child's human capital. The child's human capital is given by:

$$
h_{C}=e\left(1-l_{i}\right) .
$$

\footnotetext{
${ }^{7}$ For an overview of the economic literature on child labor, see the seminal paper by Basu and Van (1998) and the surveys by Basu (1999) and Edmonds (2008). The dynastic model of child labor developed here is based on the macroeconomic models of Doepke (2004) and Doepke and Krueger (2006).
} 
We can think of $e$ as a production function for human capital. One interpretation is that $1-l_{i}$ is time that children spend in school and that therefore raises their human capital. However, wider interpretations are also possible; for example, one component of human capital is health, and $e$ might represent the detrimental effects of child labor on future health. The child's preferences are given by:

$$
V_{C}(h)=u\left(c_{C}(h)\right)
$$

Of course, in a dynamic dynastic setting the child's utility would have the same functional form as that of the parent, with an additional term for the utility of the grandchildren.

For illustration, I will adopt particular functional forms. Parental consumption is given by:

$$
c_{P}=h+l
$$

That is, the wage is equal to one per unit of human capital, and children's human capital is normalized to one. Alternatively, we can abstract from labor markets altogether and interpret (4) as a linear production function that is available to each household.

The production function for education is assumed to be linear:

$$
e(1-l)=1-l
$$

Given that there are no grandchildren, the children's consumption is given by:

$$
c_{C}=h_{C}=1-l
$$

We also assume that the utility function is logarithmic:

$$
u_{i}(c)=\ln (c) .
$$




\subsection{Unconstrained Equilibrium}

We can now characterize the outcome in this economy if parents are unconstrained in the choice of their child's labor supply.

Proposition 1 (Unconstrained Equilibrium) In the unconstrained equilibrium, parents choose the following child labor supply $l_{i}$ :

$$
l_{i}=\max \left\{1-z_{i}\left(1+h_{i}\right), 0\right\}
$$

Proof: The parent's optimization problem is:

$$
\max _{0 \leq l_{i} \leq 1}\left\{\left(1-z_{i}\right) \ln \left(h_{i}+l_{i}\right)+z_{i} \ln \left(1-l_{i}\right)\right\} .
$$

The first-order condition for an interior optimum is:

$$
\frac{1-z_{i}}{h_{i}+l_{i}}=\frac{z_{i}}{1-l_{i}}
$$

which yields:

$$
l_{i}=1-z_{i}\left(1+h_{i}\right) .
$$

This condition together with the non-negativity constraint on $l_{i}$ gives the result.

As intuition suggests, a parent that is entirely selfish $\left(z_{i}=0\right)$ will always set child labor to the maximum level, $l_{i}=1$. Altruistic parents will leave at least some time for their child's education, $l_{i}<1$, and the more so the higher their own human capital $h_{i}$ is.

\section{Exploitation and Social Welfare}

\subsection{Defining Exploitation Relative to a Social Welfare Function}

Having described the unconstrained outcome in the economy, I now would like to consider ethical criteria for evaluating the equilibrium allocation. Is it appro- 
priate to say that children are being exploited in this world? For the purposes of the discussion, we will say that people are being exploited if they are unfairly used for the benefit of others. In the specific case of a labor relationship, exploitation happens if one person forces another to work without adequate compensation.

At first sight, it may then appear that in our model child labor amounts to exploitation by definition, given that one economic agent (the parent) imposes a work requirement on the other (the child), and no formal compensation is provided. But this does not rhyme with common sense: the parent does care about the child after all, and if $z$ is close to one, the parent would be willing to endure great suffering for the welfare of the child. It would be difficult to argue that a small amount of child labor that helps to provide subsistence income to the parent represents exploitation. It is true that in the model the child does not receive formal compensation for the labor. However, it is also true that the parent presumably incurred expenses and effort in raising the child (which is implicit in the adult budget constraint), and child labor could be viewed as compensation for such efforts.

Given these arguments, it appears that the question of whether child labor is exploitation is not an either-or question; rather, the answer should depend on the degree of altruism $z$. A relationship where one agent controls the labor supply of the other may still not represent exploitation as long as the controlling agent cares sufficiently about the controlled agent. Of course, what "sufficiently" means here depends on the meaning of "fairness" in the definition of exploitation.

As outlined in the introduction, the position adopted here is that "exploitation" needs to be judged relative to some social welfare function. For a given social welfare function, I define exploitation as follows:

Definition 1 (Exploitation) For a given social welfare function, child labor is considered exploitation if the following conditions are satisfied:

1. A a child is required to work more than what the social welfare function prescribes.

2. The additional work benefits the parent relative to the social optimum. 
Of course, the content of the definition depends on the social welfare function. Rather than trying to give one specific meaning to the term exploitation, the purpose of the definition is the reverse: I would like to compare different possible social welfare functions in terms of their implications for the meaning of exploitation, and then use our intuitive understanding of exploitation to determine which social welfare function most closely matches this understanding. Thus, the analysis will help determine what kind of social welfare function may usefully represent the moral intuitions behind the common-language use of exploitation.

\subsection{The Dynastic Social Welfare Function}

We limit attention to social welfare functions that are utilitarian in the sense of being functions of the utilities of the members of the society:

$$
\mathrm{SWF}=f\left(\left\{V_{P, i}, V_{C, i}\right\}\right) .
$$

The social optimum is the allocation that maximizes the social welfare function subject to resource constraints:

Definition 2 (Social Optimum) The social optimum given a social welfare function $f$ is the allocation that solves the following problem:

$$
\max \left\{f\left(\left\{V_{P, i}, V_{C, i}\right\}\right)\right\}
$$

subject to (1) to (7) above.

We will start with the social welfare function that is most commonly employed in dynastic economic models of the kind used here, namely what I term the dynastic social welfare function. This function is given by the sum of the utilities of the parents, without directly accounting for the children (given that they are already included in their parents' utility). This social welfare function is: ${ }^{8}$

\footnotetext{
${ }^{8}$ The dynastic social welfare function goes back to Becker and Barro (1988) and is related to the concept of $\mathcal{A}$-efficiency in Golosov, Jones, and Tertilt (2007).
} 
Definition 3 (Dynastic Social Welfare Function) The dynastic social welfare function is given by:

$$
S W F_{\text {Dynastic }}=\sum_{i} V_{P, i} \text {. }
$$

While this social welfare function is commonly applied, it implies that as long as markets are complete and there are no externalities, the decentralized equilibrium coincides with the social optimum. Thus, parents treat their children exactly as the social welfare function prescribes, and in this sense there is no exploitation.

Proposition 2 (No Exploitation under Dynastic Social Welfare Function) Under the dynastic social welfare function, the social optimum coincides with the unconstrained equilibrium.

Proof: The social welfare function is a sum of the individual objective functions that underly the unconstrained equilibrium, the constraint set is the same, and there is no interaction between different dynasties, implying that the optimum is the same as well.

This finding reflects the familiar First Welfare Theorem, namely that in the absence of externalities and market incompleteness equilibrium outcomes are Pareto optimal. Of course, Pareto optimal is defined here relative to only the parents' utility, but the same judgement is included in the dynastic social welfare function. We could generate a different result with the same welfare function by introducing market failures. To illustrate, consider an extension of the model with a human capital externality. All dynasties are identical with the same altruism factor $z$ and same initial human capital $h$. The utility functions and the production function for human capital are as above. However, I now assume that production in the second period (when the children are adult) involves a human-capital externality:

$$
c_{C}=\sqrt{h_{C}} \sqrt{h_{C}} .
$$

That is, the children's consumption depends not just on their own human capital $h_{C}$, but also on the average human capital $\bar{h}_{C}$ in the population. Households are not compensated for their contribution to average human capital in the economy; 
thus, a classic externality is now present in the model. The externality leads to a wedge between the equilibrium allocation of labor and the socially optimal allocation.

\section{Proposition 3 (Equilibrium and Social Optimum with Human-Capital Externality)} In the model with a human capital externality as in (8), the equilibrium labor allocation is:

$$
l=\max \left\{\frac{2}{2-z}\left(1-z\left(1+\frac{h}{2}\right)\right), 0\right\},
$$

whereas the socially optimal allocation is:

$$
l=\max \{1-z(1+h), 0\} .
$$

Thus, all children work more in the equilibrium allocation compared to the social optimum (as long as equilibrium child labor is positive).

Proof: The parent's optimization problem is (after plugging all constraints into the objective and omitting constants):

$$
\max _{0 \leq l \leq 1}\left\{(1-z) \ln (h+l)+\frac{1}{2} z \ln (1-l)\right\} .
$$

The first-order condition for an interior optimum is:

$$
\frac{1-z}{h+l}=\frac{z}{2(1-l)},
$$

which yields:

$$
l=\frac{2}{2-z}-\frac{z}{2-z}(2+h)=\frac{2}{2-z}\left(1-z\left(1+\frac{h}{2}\right)\right) .
$$

This condition together with the non-negativity constraint on $l$ gives the result.

For the social optimum, the planner recognizes that $h_{C}=\bar{h}_{C}$ in equilibrium, implying that children's consumption is still given by:

$$
c_{C}=h_{C}
$$


as in (8), so that the social optimum coincides with the equilibrium allocation characterized in Proposition 1.

Thus, in the model with the human-capital externality child labor is inefficiently high in the equilibrium allocation. However, even though children work too much, the model still does not fulfill our definition of exploitation. The reason is that the increased labor supply of the children in the equilibrium allocation does not actually make the parents better off relative to the social optimum, which was the second requirement in the definition of exploitation. In fact, the parents are worse off in the equilibrium: all economic agents, parents and children, are negatively affected by the presence of the externality. The following corollary summarizes the result.

Corollary 1 (No Exploitation despite Human-Capital Externality) In the model with a human capital externality, children work more than in the social optimum, but nevertheless child labor does not constitute exploitation in the sense of Definition 1.

This example should make clear that it is difficult to satisfy the definition of exploitation when the usual dynastic social welfare function is used. If all parents are identical, the social optimum under this welfare function delivers the highest possible utility to the parents given the constraints of the economy, so that they cannot be made better off by exploiting their children through child labor in some way. A parallel argument would apply to other forms of market failures. ${ }^{9}$ We therefore move on to alternative welfare functions where the tight link between social optima and parental welfare no longer applies.

\subsection{A Social Welfare Function with Direct Weight on Children}

One can argue that the basic defect of the dynastic social welfare function is that it places direct weight only on the parents, while ignoring the children. Thus, let us consider an alternative welfare function where the utility of children enters

\footnotetext{
${ }^{9}$ For example, Baland and Robinson (2000) focus on capital market imperfections, namely the inability of parents to borrow against their children's future earnings.
} 
directly, in addition to the indirect weighting through parental altruism. Among others, this social welfare function is advocated by Farhi and Werning (2007). ${ }^{10}$ We term this welfare function the inclusive social welfare function.

Definition 4 (Inclusive Social Welfare Function) The inclusive social welfare function is given by:

$$
S W F_{\text {Inclusive }}=\sum_{i} V_{P, i}+\gamma \sum_{i} V_{C, i}
$$

Here $\gamma>0$ is the additional, direct weight attached to the utility of the children.

The inclusive welfare function leads to the opposite conclusion of the dynastic welfare function: as long as children are working at all, this always represents exploitation, regardless of the degree of altruism $z$. To establish this result, I revert to the original model without a human-capital externality (allowing for externalities would not alter the results).

Proposition 4 (Social Optimum under Inclusive Welfare Function) Under the inclusive social welfare function, the socially optimal child-labor supply is given by:

$$
l_{i}=\max \left\{\frac{1}{1+\gamma}\left(1-z_{i}(1+h)-\gamma h\right), 0\right\} .
$$

Thus, if child labor is positive in equilibrium, the socially optimal child-labor supply is lower than equilibrium labor supply (which is characterized in Proposition 1).

Proof: Given that there is no interaction across dynasties, we can solve for the socially optimal child labor supply for each dynasty individually. For dynasty $i$, the problem of maximizing social welfare is given by:

$$
\max _{0 \leq l_{i} \leq 1}\left\{\left(1-z_{i}\right) \ln \left(h_{i}+l_{i}\right)+\left(z_{i}+\gamma\right) \ln \left(1-l_{i}\right)\right\} .
$$

\footnotetext{
${ }^{10}$ See also Caplin and Leahy (2004) for an argument why a similar welfare function may be applied to an individual's lifetime utility, and Bernheim (1989) for a comparison of equilibria and social optima under this welfare function.
} 
The first-order condition for an interior optimum is:

$$
\frac{1-z_{i}}{h_{i}+l_{i}}=\frac{z_{i}+\gamma}{1-l_{i}}
$$

which yields:

$$
l_{i}=\frac{1}{1+\gamma}\left(1-z_{i}(1+h)-\gamma h\right) .
$$

This condition together with the non-negativity constraint on $l_{i}$ gives the result.

Corollary 2 (Exploitation under Inclusive Welfare Function) Under the inclusive social welfare function, if child labor is positive in the unconstrained equilibrium, it constitutes exploitation in the sense of Definition 1.

Proof: Proposition 4 shows that if child labor is positive in equilibrium, it has to be lower in the social optimum under the inclusive welfare criterion, satisfying the first requirement of the definition. In addition, the equilibrium allocation yields the highest feasible utility for the parents, implying that parents are better off in equilibrium compared to the social optimum, which satisfies the second requirement of the definition.

The result under the inclusive social welfare function is equally unsatisfactory as our findings under the dynastic social welfare function. Any child labor is now considered to amount to exploitation. No matter how much the parent cares about the child, from the perspective of the social welfare function the parent does not care enough. The technical reason is that the social altruism is in addition to parental altruism.

More generally, the welfare criterion implies that parents give too little to their children in any dimension, be it protection from child labor, consumption, human capital investment, or bequests. Whereas under the dynastic social welfare function parents can do no wrong, under the inclusive social welfare function they can do no right. Such a blanket condemnation appears equally unattractive as the blanket approval of parental actions that is implied by the dynastic social welfare function. The next proposed welfare criterion tries to find a middle ground between these two extremes. 


\subsection{A Social Welfare Function with Universal Altruism}

At heart, a social welfare function describes how we feel about other people's choices. In our specific setting, what is at issue is how people feel about the appropriate distribution of resources between parents and children in other families. It would seem plausible that in making this judgement, people apply the same altruism factor $z_{i}$ that they apply in their own family. Thus, each individual would possess a social welfare function where the same weight $z_{i}$ is attached to the welfare of all children, regardless of the preferences of the parents of these children. Social judgements would then depend on which family's social welfare function is used. A simple possibility is to sum all families' welfare functions, in the same way that the dynastic welfare function sums the utility of all dynasty heads. We term this welfare function the universally altruistic welfare function. The social discount factor $\bar{z}$ that is being applied to all children is the average of all individual altruism factors:

$$
\bar{z}=\frac{1}{N} \sum_{i} z_{i}
$$

Here $N$ is the total number of dynasties.

Definition 5 (Social Welfare Function with Universal Altruism) The universally altruistic social welfare function is given by:

$$
\begin{aligned}
\text {SWF}_{\text {Universal Altruism }} & =\sum_{i}\left[(1-\bar{z}) u\left(c_{P, i}\right)+\bar{z} V_{C, i}\right] \\
& =\sum_{i} \frac{1-\bar{z}}{1-z_{i}} V_{P, i}+\sum_{i}\left(\bar{z}-\frac{z_{i}(1-\bar{z})}{1-z_{i}}\right) V_{C, i} \\
& =\sum_{i} \frac{1-\bar{z}}{1-z_{i}} V_{P, i}+\sum_{i}\left(\frac{\bar{z}-z_{i}}{1-z_{i}}\right) V_{C, i} .
\end{aligned}
$$

If all families have identical preferences, $z_{i}=\bar{z}$ for all $i$, the welfare function under universal altruism reduces to the dynastic welfare function. In that case, all families agree on the proper consideration of children's welfare, and there is no exploitation. If there is heterogeneity across families in $z_{i}$, results change. Chil- 
dren from dynasties with low altruism, $z_{i}<\bar{z}$, receive additional direct weight in the welfare function. The opposite applies to children from families with high altruism: the judgement implicit in the social welfare function is that these children are treated too well relative to their parents (they are "spoiled"), so that their utility enters the social welfare function with a negative sign.

\section{Proposition 5 (Social Optimum under Universally Altruistic Welfare Function)} Under the universally altruistic social welfare function, the socially optimal child-labor supply is given by:

$$
l_{i}=\max \left\{1-\bar{z}\left(1+h_{i}\right), 0\right\} .
$$

Thus, if child labor is positive in equilibrium, the socially optimal child labor supply is lower than equilibrium labor supply (which is characterized in Proposition 1) in families where $z_{i}<\bar{z}$, and higher where $z_{i}>\bar{z}$.

Proof: Given that there is no interaction across dynasties, we can solve for the socially optimal child labor supply for each dynasty individually. The maximization problem is of form of the individual decision problem in Proposition 1 with $z_{i}$ replaced by $\bar{z}$, which gives the result.

Corollary 3 (Exploitation under Universally Altruistic Welfare Function) Under the universally altruistic social welfare function, if in a given family we have $z_{i}<\bar{z}$ and $l_{i}>0$, the child labor in this family constitutes exploitation in the sense of Definition 1.

Proof: Comparing Propositions 1 and 5, we see that child labor is higher than in the social optimum if $z_{i}<\bar{z}$ and $l_{i}>0$. Moreover, the parent achieves higher utility in the unconstrained equilibrium compared to the social optimum, which satisfies the second requirement of the definition.

Thus, the universally altruistic welfare criterion delivers a non-trivial judgement of whether a given instance of child labor amounts to exploitation.

A potential weakness of the criterion is that it is based on averaging individual judgements. From the perspective of any given adult, exploitation is taking place if another parent cares less about the child than the adult him- or herself. It is 
not obvious why the average of such judgements in the population should have a special moral status. However, such marginal judgements cannot be entirely avoided, and in this case we have the advantage that there is a clear link between individual preferences and the social welfare function.

\subsection{A Social Welfare Function with Minimum Altruism}

A shortcoming of the social welfare function with universal altruism is that it implies that the socially optimal allocation differs from the equilibrium allocation for any family with $z_{i} \neq \bar{z}$, not just those for who $z_{i}<\bar{z}$. For families with $z_{i}>\bar{z}$, the social optimum prescribes higher child labor than what occurs in equilibrium. This implication is problematic, because it violates the Pareto criterion: both parent and child are better off in the equilibrium than in the social optimum, the child because it works less and gets more human capital, the parent because it cares sufficiently about the child to prefer this outcome to more personal consumption. One can avoid this implication by specifying the social welfare function such that it respects the parent's preferences as long as $z_{i} \geq \bar{z}$, and imposes $\bar{z}$ only for those families where $z_{i}<\bar{z}$. The asymmetry can be justified because it is the parents who are imposing decisions on children, and hence it is the children that need to be protected from exploitation. If parents reveal a preference for giving even more resources to their children than recommended by the social welfare function, that should be respected. The social welfare function incorporating this feature can be expressed as follows:

Definition 6 (Social Welfare Function with Minimum Altruism) The minimumaltruism social welfare function is given by:

$$
\begin{aligned}
S W F_{\text {Minimum Altruism }}= & \sum_{i}\left(1-\max \left\{z_{i}, \bar{z}\right\}\right) u\left(c_{P, i}\right)+\max \left\{z_{i}, \bar{z}\right\} V_{C, i} \\
= & \sum_{i} I\left(z_{i} \geq \bar{z}\right) V_{P, i} \\
& +\sum_{i} I\left(z_{i}<\bar{z}\right)\left(\frac{1-\bar{z}}{1-z_{i}} V_{P, i}+\left(\frac{\bar{z}-z_{i}}{1-z_{i}}\right) V_{C, i}\right),
\end{aligned}
$$


where $I(\cdot)$ is the indicator function.

Proposition 6 (Social Optimum under Minimum Altruism) Under the minimum altruism social welfare function, the socially optimal child-labor supply is given by:

$$
l_{i}=\max \left\{1-\max \left\{z_{i}, \bar{z}\right\}\left(1+h_{i}\right), 0\right\} .
$$

Proof: The result follows from combining the results in Propositions 1 and 5.

Note that in principle the welfare criterion could be applied using a $\bar{z}$ different from average altruism in the population. The spirit of the criterion is that exploitation is said to take place when parents display less than some specific minimum amount of altruism towards their children, and in principle this minimum could be determined at a different level than the average.

An attractive feature of this criterion is that its implications rhyme well with common sense perceptions of what amounts to exploitation as well as with the nature of legal restrictions in the area of child labor. For example, exploitation would be more likely when the legal guardian of a child is not actually a parent and is therefore less likely to display sufficient altruism. And indeed, common examples of exploitative child labor include cases where children are removed from their parents (as in child trafficking), and much regulation imposes minimum standards for the treatment of children that would not be binding for families with typical levels of altruism. Thus, the welfare criterion is closer to a conventional understanding of exploitation than the more commonly applied dynastic social welfare function.

\subsection{Dynamic Extension of Minimum Altruism}

So far I have limited attention to a static setting with a single generation of parents and children. I now briefly outline how the preferred welfare criterion would extend to an environment with successive generations of people. Each dynasty consists of a sequence of members, i.e., parents, children, grandchildren and so on, where the generation is indexed by $t \in\{0,1,2, \ldots\}$. The technologies 
for producing goods and human capital are as before. We assume that the intergenerational altruism factor $z_{i}$ is fixed within each dynasty (although this could be generalized). The lifetime utility of generation $t$ is given recursively by:

$$
V_{t, i}\left(h_{t, i}\right)=\left(1-z_{i}\right) u\left(c\left(h_{t, i}, l_{t, i}\right)\right)+z_{i} V_{t+1, i}\left(h_{t+1, i}\right) .
$$

The law of motion for human capital in the dynasty is given by:

$$
h_{t+1, i}=e\left(1-l_{t, i}\right)
$$

Applying the preceding arguments to the dynastic setting, minimum altruism should be defined as follows:

Definition 7 (Social Welfare Function with Dynamic Minimum Altruism) The minimum altruism social welfare function in the dynamic setting is given by:

$$
\begin{aligned}
S W F_{\text {Dynamic Minimum Altruism }}= & \sum_{i}\left(1-\max \left\{z_{i}, \bar{z}\right\}\right) \sum_{t=0}^{\infty}\left(\max \left\{z_{i}, \bar{z}\right\}\right)^{t} u\left(c\left(h_{t, i}, l_{t, i}\right)\right) \\
= & \sum_{i} I\left(z_{i} \geq \bar{z}\right)\left(1-z_{i}\right) \sum_{t=0}^{\infty} z_{i}^{t} u\left(c\left(h_{t, i}, l_{t, i}\right)\right) \\
& +\sum_{i} I\left(z_{i}<\bar{z}\right)(1-\bar{z}) \sum_{t=0}^{\infty} \bar{z}^{t} u\left(c\left(h_{t, i}, l_{t, i}\right)\right) \\
= & \sum_{i} I\left(z_{i} \geq \bar{z}\right) V_{0, i} \\
& +\sum_{i} I\left(z_{i}<\bar{z}\right) \frac{1-\bar{z}}{1-z_{i}}\left[V_{0, i}\left(h_{0, i}\right)+\sum_{t=1}^{\infty} \bar{z}^{t-1}\left(\bar{z}-z_{i}\right) V_{t, i}\right] .
\end{aligned}
$$

Thus, the social welfare function is still of a utilitarian form, i.e., it is a weighted sum of the lifetime utilities of all people in the economy. Future generations of dynasties with sufficient altruism $\left(z_{i} \geq \bar{z}\right)$ are considered only through the altruism of the head of the dynasty. In contrast, the welfare function places direct weight on future members of dynasties for whom altruism is below the minimum. 


\section{Conclusions}

In this paper, I have explored how the concept of exploitative child labor can be made precise in an economic model in a way that is consistent with the conventional understanding of exploitation. In order to accomplish this, exploitation was defined relative to a specific utilitarian social welfare function. I defined child labor to amount to exploitation if (i) a child works more than in the social optimum defined by the welfare function, and (ii) the additional work benefits the parent relative to the social optimum.

The analysis shows that under the standard dynastic social welfare function, in which the welfare of children enters only through parental altruism, child labor is never exploitative. This is true even if there are market imperfections that lead to an inefficiently high level of child labor. The finding leads to the conclusion that to allow for the possibility of exploitation, the social welfare function has to put higher weight on the welfare of at least some children than the parents do. However, if the social welfare function places additional weight on all children (inclusive welfare function), the equally extreme conclusion arises that all child labor amounts to exploitation, regardless of how much the parent cares about the child.

Given these results, the social welfare function that best represents the conventional notion of exploitation is the minimum altruism social welfare function. The welfare function is characterized by a single parameter $\bar{z}$, which is the minimum relative weight that is attached to the welfare of each child. It is a "minimum" weight because some parents may attach an even higher weight to their children, and the minimum social welfare function respects this preference. However, child labor in families where the parents attach a weight of less than $\bar{z}$ to their children is considered to be exploitative under this criterion. Whether child labor in a given instance amounts to exploitation is therefore a non-trivial question that depends on the totality of the circumstances of the parent and the child.

The general concept of minimum altruism leaves open how the minimum level $\bar{z}$ is to be chosen. In the formal analysis I have used the average of the individual altruism factors $z_{i}$ as a potential choice for $\bar{z}$, but there is no specific reason why 
the average should have special significance from an ethical perspective. One way to proceed is to envision $\bar{z}$ as an individual ethical choice. That is, a person's $\bar{z}$ would be the altruism factor such that this person would regard the child-labor choices of a parent with $z_{i}=\bar{z}$ is being just on the verge of exploitation. While such a definition would be appropriate to make up one's own mind about exploitation, it may be desirable to achieve a broader consensus on the appropriate $\bar{z}$ in a society. ${ }^{11}$ After all, the very concept of exploitation suggests that exploitative child labor should ideally be avoided. This might require political action, which, in turn, would have to rely on agreement on what $\bar{z}$ should be used to define exploitative child labor. A veil of ignorance a la Rawls may be useful to achieve some consensus on $\bar{z}$.

As a practical matter, actual political debates on regulation of social issues such as child labor bear some resemblance to what would be expected in a discussion informed by the minimum altruism criterion. For example, early regulations of child labor were specifically designed to deal with extreme forms of exploitation, while leaving child labor in a typical family (i.e., family based agriculture) unaffected (see Doepke and Zilibotti 2005). ${ }^{12}$ Similarly, early expansions of women's rights in the nineteenth century focused on protecting the wives and children of a small group irresponsible husbands (see Doepke and Tertilt 2009). From this perspective, the minimum altruism concept may prove useful for other politicaleconomy issues connected to intergenerational justice as well.

To broaden the possible applications, the framework could be extended in a number of directions. It would be interesting to explore the implications of two-sided altruism as in Kimball (1987). In addition, given the intergenerational focus introducing endogenous fertility would be useful. ${ }^{13}$ Regarding the choice of the minimum altruism level $\bar{z}$, the implications of technical change are a salient issue. For example, if technical change leaves future generations much better off,

\footnotetext{
${ }^{11}$ There is a related discussion on what the appropriate social discount should be. This is particularly relevant for policies with very long-term consequences, such as issues connected to climate change. See Weitzman (2001) for a discussion of the implications of disagreement on the social discount rate.

${ }^{12}$ For recent studies of the political economy of child labor, see Basu and Zarghamee (2009) and Doepke and Zilibotti (2010).

${ }^{13}$ In this vein, Schoonbroodt and Tertilt (2011) explore whether insufficient rights of parents over their children may lead to fertility bing inefficiently low.
} 
one might argue that a lower weight should be attached to them in the social welfare function. These extensions are left to future research.

\section{References}

Baland, Jean-Marie, and James Robinson. 2000. "Is Child Labor Inefficient?" Journal of Political Economy 108 (4): 663-679.

Barro, Robert J. 1974. "Are Government Bonds Net Wealth?" Journal of Political Economy 82 (6): 1095-117.

Barro, Robert J., and Gary S. Becker. 1989. "Fertility Choice in a Model of Economic Growth." Econometrica 57 (2): 481-501.

Basu, Kaushik. 1999. "Child Labor: Cause, Consequence, and Cure, with Remarks on International Labor Standards." Journal of Economic Literature 37 (3): 1083-1117.

Basu, Kaushik, and Pham Hoang Van. 1998. "The Economics of Child Labor." American Economic Review 88 (3): 412-427.

Basu, Kaushik, and Homa Zarghamee. 2009. "Is Product Boycott a Good Idea for Controlling Child Labor? A Theoretical Investigation." Journal of Development Economics 88 (2): 217-20.

Becker, Gary S., and Robert J. Barro. 1988. "A Reformulation of the Economic Theory of Fertility." Quarterly Journal of Economics 103 (1): 1-25.

Bernheim, B. Douglas. 1989. "Intergenerational Altruism, Dynastic Equilibria and Social Welfare." Review of Economic Studies 56 (1): 119-28.

Caplin, Andrew, and John Leahy. 2004. "The Social Discount Rate." Journal of Political Economy 112 (6): 1257-68.

de la Croix, David, and Philippe Michel. 2002. A Theory of Economic Growth: Dynamics and Policy in Overlapping Generations. Cambridge: Cambridge University Press.

Doepke, Matthias. 2004. "Accounting for Fertility Decline During the Transition to Growth." Journal of Economic Growth 9 (3): 347-83. 
Doepke, Matthias, and Dirk Krueger. 2006. "Origins and Consequences of Child Labor Restrictions: A Macroeconomic Perspective." NBER Working Paper No. 12665.

Doepke, Matthias, and Michèle Tertilt. 2009. “Women's Liberation: What's in It for Men?" Quarterly Journal of Economics 124 (4): 1541-91.

Doepke, Matthias, and Fabrizio Zilibotti. 2005. "The Macroeconomics of Child Labor Regulation." American Economic Review 95 (5): 1492-524.

- 2010. “Do International Labor Standards Contribute to the Persistence of the Child Labor Problem?" Journal of Economic Growth 15 (1): 1-31.

Edmonds, Eric V. 2008. "Child Labor." Chapter 11 of Handbook of Development Economics, edited by T. Paul Schultz and John Strauss, Volume 4. Amsterdam: North Holland.

Farhi, Emmanuel, and Iván Werning. 2007. "Inequality and Social Discounting." Journal of Political Economy 115 (3): 365-402.

Golosov, Mikhail, Larry E. Jones, and Michèle Tertilt. 2007. "Efficiency with Endogenous Population Growth." Econometrica 75 (4): 1039-71.

Holleran, Phillip M. 1995. "Child Labor and Exploitation in Turn-of-theCentury Cotton Mills." Explorations in Economic History 30:485-500.

Horrell, Sara, and Jane Humphries. 1995. "The Exploitation of Little Children: Child Labor and the Family Economy in the Industrial Revolution." Explorations in Economic History 32:485-516.

Kimball, Miles S. 1987. "Making Sense of Two-Sided Altruism." Journal of Monetary Economics 20 (2): 301-26.

Roemer, John E. 1985. "Should Marxists Be Interested in Exploitation?" Philosophy \& Public Affairs 14 (1): 30-65.

Schoonbroodt, Alice, and Michèle Tertilt. 2011. "Property Rights and Efficiency in OLG Models with Endogenous Fertility." Unpublished Manuscript, University of Mannheim.

Sen, Amartya. 1979. "Utilitarianism and Welfarism." The Journal of Philosophy 76 (9): 463-89. 
Weitzman, Martin L. 2001. "Gamma Discounting." American Economic Review 91 (1): 260-71. 